\title{
No Muscle Depletion with High Visceral Fat as a Novel Beneficial Biomarker of Sorafenib for Hepatocellular Carcinoma
}

\author{
Issei Saeki ${ }^{a}$ Takahiro Yamasaki $^{\mathrm{b}}$ Masaki Maeda $^{\mathrm{a}}$ Reo Kawano $^{\mathrm{c}}$ \\ Takuro Hisanaga a, d Takuya Iwamoto ${ }^{a}$ Toshihiko Matsumoto a, b \\ Isao Hidaka ${ }^{a}$ Tsuyoshi Ishikawa ${ }^{a}$ Taro Takami ${ }^{a}$ Isao Sakaida ${ }^{a}$ \\ ${ }^{a}$ Department of Gastroenterology and Hepatology, Yamaguchi University Graduate School \\ of Medicine, Ube, Japan; ${ }^{b}$ Department of Oncology and Laboratory Medicine, Yamaguchi \\ University Graduate School of Medicine, Ube, Japan; ${ }^{c}$ Center for Clinical Research, \\ Yamaguchi University Hospital, Ube, Japan; ${ }^{\mathrm{d} D e p a r t m e n t}$ of Medical Education, Yamaguchi \\ University Graduate School of Medicine, Ube, Japan
}

\section{Keywords}

Body composition - Hepatocellular carcinoma - No muscle depletion · Sorafenib - Visceral fat area

\begin{abstract}
Background: Sorafenib is a standard therapy for patients with advanced hepatocellular carcinoma (HCC). However, no predictive biomarkers of sorafenib efficacy have been discovered. Herein, we investigated the impact of body composition, such as skeletal muscle and visceral fat, on the prognosis of advanced HCC patients treated with sorafenib. Methods: We enrolled 100 patients with advanced HCC treated with sorafenib. Prior to receiving sorafenib therapy, skeletal muscle index (SMI) and visceral fat area (VFA) were measured using computed tomography at the third lumbar vertebra and umbilical level, respectively. Muscle depletion was defined as an SMI value $<42 \mathrm{~cm}^{2} / \mathrm{m}^{2}$ in men and $<38 \mathrm{~cm}^{2} / \mathrm{m}^{2}$ in women. High VFA (H-VFA) was defined as a value $\geq 100 \mathrm{~cm}^{2}$. In addition to SMI and VFA, we also analyzed various clinical parameters as potential prognostic factors. Results: Multivariate analysis showed that having a tumor number $<7$ (hazard ratio $[\mathrm{HR}]=0.409, p<0.001$ ), absence of extrahepatic spread (EHS) (HR $=0.562, p<0.001)$, absence of muscle depletion (HR $=0.498, p=0.006)$, and H-VFA ( $H R=0.556, p=0.031)$ were significant factors for long-term survival. Therefore, we evaluated the prognosis of those with no muscle depletion with H-VFA. The no muscle depletion with H-VFA group showed significantly longer survival than the other group (median survival time 15.6 vs. 11.0 months, $p=0.003$ ). Multivariate analysis showed that having a tumor num-
\end{abstract}


ber $<7(H R=0.454, p=0.001)$, absence of EHS (HR $=0.511, p=0.008)$, and no muscle depletion with H-VFA ( $\mathrm{HR}=0.454, p=0.002$ ) were significant predictors of survival. Conclusions: We identified no muscle depletion with H-VFA as a novel biomarker for advanced HCC patients treated with sorafenib.

(C) 2018 S. Karger AG, Basel

\section{Introduction}

Sorafenib is an orally multitargeted kinase inhibitor that suppresses signal transduction pathways which mediate tumor growth and angiogenesis. In large-scale phase III trials, sorafenib treatment significantly improved overall survival (OS) and time to progression in patients with advanced hepatocellular carcinoma (HCC) [1, 2]. Therefore, sorafenib has been widely used as a first-line standard systemic agent and is the currently recommended standard of care for the treatment of advanced HCC [3].

However, there are several weak points in sorafenib treatment. First, the response rate to sorafenib is low at approximately $2-3 \%$ and survival prolongation is short at $<3$ months $[1,2]$. Second, most patients present with various adverse events of sorafenib, with drugrelated grade 3 or 4 adverse events, according to the National Institute of Health's Common Terminology Criteria for Adverse Events version 3.0, observed in $37.4 \%$ of Japanese patients participating in the GIDEON study [4]. Finally, as sorafenib treatment is expensive, its associated cost represents a limitation [5]. Although several studies have investigated predictive biomarkers of sorafenib efficacy, there have been no established predictive biomarkers [6-9]. Therefore, a simple biomarker for the prediction of sorafenib efficacy would be clinically advantageous.

Body composition characteristics, such as skeletal muscle and visceral fat, are considered to be prognostic factors for various diseases, including cancer [10]. In particular, sarcopenia has been reported to be an independent predictor of survival in patients with lung, gastrointestinal, pancreatic, and colorectal cancer as well as HCC [11-15]. For HCC patients receiving sorafenib therapy, it has been reported that skeletal muscle depletion is an independent prognostic factor [16-18]. However, visceral fat area (VFA) is a controversial topic regarding its effects on survival of patients with HCC [15, 19-21]. In addition, there have been no studies in relation to both skeletal muscle and visceral fat in HCC patients treated with sorafenib.

In this study, we retrospectively analyzed the impact of body composition, in relation to both skeletal muscle and visceral fat, on the prognosis of advanced HCC patients treated with sorafenib, with the aim of developing a beneficial biomarker of sorafenib.

\section{Patients and Methods}

Patients

Between September 2009 and July 2016, sorafenib was administered to 107 patients who were admitted to our hospital with unresectable HCC. A total of 100 patients who underwent computed tomography (CT) imaging within 1 month before the initiation of sorafenib treatment were enrolled in this study. The diagnosis of HCC was based on imaging results and elevated serum levels of alpha-fetoprotein and/or des-gamma-carboxy prothrombin. We assessed HCC tumor stage using the criteria of the Liver Cancer Study Group of Japan, 6th edition [22]. Sorafenib was administered to patients with advanced HCC who were confirmed to be transcatheter arterial chemoembolization refractory, showed evidence of extrahepatic spread (EHS), and/or had macrovascular invasion. In principle, sorafenib was administered orally at a daily dose of $800 \mathrm{mg}$ for as long as possible; however, it was withheld at a daily dose of $400 \mathrm{mg}$ according to liver function. 


\section{Liver Cancer}

\begin{tabular}{l|l|}
\hline Liver Cancer 2018;7:359-371 \\
\hline DOI: 10.1159/000487858 & $\begin{array}{l}\text { (c) 2018 S. Karger AG, Basel } \\
\text { www.karger.com/lic }\end{array}$ \\
\hline
\end{tabular}

Saeki et al.: Body Composition as a Sorafenib Biomarker

Assessment of Skeletal Muscle and Visceral Fat

All patients underwent CT within 1 month prior to receiving sorafenib therapy. The degrees of proportional skeletal muscle area and VFA were measured from the patients' CT images. Using an AZE 3D work station (AZE Virtual Place Raijin; AZE Ltd., Tokyo, Japan), we analyzed the cross-sectional CT images at the third lumbar vertebra level to determine skeletal muscle area, as well as at the umbilical level to determine VFA. Skeletal muscle was identified and quantified by Hounsfield unit (HU) thresholds of -29 to +150 (water is defined as $0 \mathrm{HU}$ and air as 1,000 HU) [23]. VFA was calculated by counting pixels with densities of -190 to $-30 \mathrm{HU}$ [24]. Skeletal muscle mass was normalized for height in $\mathrm{m}^{2}$ and expressed as skeletal muscle index (SMI) $\left(\mathrm{cm}^{2} / \mathrm{m}^{2}\right)$. Using values for SMI, muscle depletion was defined as a value $<42 \mathrm{~cm}^{2} / \mathrm{m}^{2}$ in men and $<38 \mathrm{~cm}^{2} / \mathrm{m}^{2}$ in women, according to the Japan Society of Hepatology criteria [25]. High VFA (H-VFA) was defined as a value of $\geq 100 \mathrm{~cm}^{2}$, and low VFA (L-VFA) was $<100 \mathrm{~cm}^{2}$ in men and women, according to the criteria for "obesity disease" as established by the Japan Society for the Study of Obesity [26]. Moreover, we calculated the skeletal muscle area at the third lumbar vertebra level and VFA at 3 and 6 months after sorafenib induction.

\section{Evaluation of Treatment Response}

The evaluation of treatment response was classified according to the modified Response Evaluation Criteria in Solid Tumors [27], based on dynamic CT or magnetic resonance imaging carried out every 3 months. The best response was considered for the response evaluation. We regarded the patients who died without evaluation of the treatment response, based on imaging, as no evaluation.

\section{Statistical Analysis}

For continuous variables, results were expressed as mean \pm standard deviation or median (interquartile range), and the differences between any two groups were evaluated with an unpaired $t$ test. Categorical variables were presented as frequency counts, and intergroup comparisons were analyzed by the $\chi^{2}$ test or the Fisher exact test. OS was calculated using the Kaplan-Meier method. Survival time was defined as the interval between the initiation of sorafenib and the last follow-up or death. The follow-up period ended on December 31,2016 . We assessed clinical pretreatment factors in the survival analysis, including age ( $<70$ or $\geq 70$ years), sex (male or female), Child-Pugh classification (A or B), tumor number ( $<7$ or $\geq 7$ ), maximum tumor size $(<40$ or $\geq 40 \mathrm{~mm})$, macrovascular invasion $(-/+)$, EHS $(-/+)$, muscle depletion (absence or presence), and VFA (H-VFA or L-VFA). Uni- and multivariate analyses of OS were performed using Cox regression models, and the results are presented as hazard ratio (HR) with 95\% confidence intervals (CIs). Statistical significance was defined as a $p$ value $<0.05$. All analyses were performed using the JMP software package v13.0 (SAS Institute, Cary, $\mathrm{NC}, \mathrm{USA}$ ).

\section{Results}

\section{Patient Characteristics}

The clinical profiles of the 100 study patients are summarized in Table 1 . The patient population consisted of 72 men and 28 women, with a mean age of $70.6 \pm 9.8$ years. Regarding liver function, 80 patients were classified as having Child-Pugh A disease and 20 as having Child-Pugh B disease. Seventy patients had stage IV disease and the remaining patients had stage II-III disease. The median tumor number and the median maximum tumor size were 7.0 and $40.5 \mathrm{~mm}$, respectively. Twenty-nine patients had macrovascular invasion and $44 \mathrm{had}$ EHS. No patients exhibited complete response, 7 (7\%) exhibited partial response, 53 (53\%) exhibited stable disease, 27 (27\%) exhibited progressive disease, and 13 (13\%) exhibited no evaluation. The response rate and the disease control rate were 7 and $60 \%$, respectively. Muscle depletion was observed in 46 of all patients (46\%) and H-VFA was found in 65 patients $(65 \%)$. 
Table 1. Patient characteristics

Number of patients

Age, years

$\operatorname{Sex}(\mathrm{M} / \mathrm{F})$

Body mass index

Etiology (HBV/HCV/alcohol/others)

Child-Pugh class (A/B)

Stage (II-III/IV) ${ }^{\mathrm{a}}$

Tumor number

Tumor size, $\mathrm{mm}$

Macrovascular invasion $(-/+)$

Extrahepatic spread $(-/+)$

Alpha-fetoprotein, ng/mL

Des-gamma carboxy prothrombin, $\mathrm{mAU} / \mathrm{mL}$

L3 SMI (M/F), $\mathrm{cm}^{2} / \mathrm{m}^{2}$

Visceral fat area, $\mathrm{cm}^{2}$

Response (CR/PR/SD/PD/NE) ${ }^{\mathrm{b}}$

Muscle depletion $(-/+)^{\mathrm{c}}$

Visceral fat area (high/low) ${ }^{\mathrm{d}}$ (c) 2018 S. Karger AG, Basel

www.karger.com/lic

Values are presented as numbers, mean \pm standard deviation, or median (interquartile range). CR, complete response; HBV, hepatitis B virus; HCV, hepatitis C virus; L3 SMI, third lumber vertebra skeletal muscle index; NE, no evaluation; PD, progressive disease; PR, partial response; SD, stable disease. ${ }^{\text {a }}$ According to the criteria of the Liver Cancer Study Group of Japan. ${ }^{b}$ Response: evaluated by modified Response Evaluation Criteria in Solid Tumors. ${ }^{\mathrm{c}}$ According to the criteria of the Japan Society of Hepatology. ${ }^{\mathrm{d}}$ According to the criteria for "obesity disease" as established by the Japan Society for the Study of Obesity.

\section{Patient Survival and Predictors of Survival}

The OS rates at 1,2 , and 3 years were $51.6,19.7$, and $17.2 \%$, respectively, with a median survival time (MST) of 12.1 months (Fig. 1a). The predictors of survival are shown in Table 2. Of the nine factors analyzed using univariate analysis, four were significant predictors of survival: Child-Pugh A ( $p=0.031)$, tumor number $<7(p<0.001)$, absence of muscle depletion $(p=0.018)$, and H-VFA ( $p=0.019)$. Patients without muscle depletion showed significantly longer survival than patients with muscle depletion (MST 13.4 vs. 10.9 months, $p=0.015$ ) (Fig. 1b). In addition, the patients with H-VFA showed significantly longer survival than those with L-VFA (MST 14.2 vs. 10.2 months, $p=0.015$ ) (Fig. 1c). Furthermore, multivariate analysis showed that a tumor number $<7$ (HR $=0.409,95 \%$ CI $0.247-0.666, p<0.001)$, absence of EHS (HR $=0.562,95 \%$ CI $0.344-0.921, p<0.001)$, absence of muscle depletion (HR $=0.498,95 \%$ CI $0.304-0.818, p=0.006$ ), and H-VFA (HR $=0.556,95 \%$ CI $0.331-0.945, p=0.031$ ) were significant prognostic factors for longer survival (Table 2).

\section{Body Composition Factors}

Both skeletal muscle and visceral fat were significantly associated with the prognosis of advanced HCC patients. Based on these results, we categorized all patients into four types: the no muscle depletion with H-VFA group $(n=38)$, the no muscle depletion with L-VFA group $(n=16)$, the muscle depletion with H-VFA group $(n=27)$, and the muscle depletion with L-VFA group $(n=19)$. When analyzing OS in the four types, survival was significantly stratified by body composition ( $p=0.010)$, and the no muscle depletion with H-VFA group showed the longest survival of the four groups (Fig. 2). In addition, MST was significantly longer in the no muscle depletion with H-VFA group than in the no muscle depletion with L-VFA group (15.6 vs. 12.1 months, $p=0.049$ ), and there were no significant differences in survival among 


\section{Liver \\ Cancer}

Fig. 1. a Cumulative survival of advanced hepatocellular carcinoma patients receiving sorafenib. The survival rates at 1, 2, 3 years were 51.6, 19.7, and 17.2\%, respectively. The MST was 12.1 months. $\mathbf{b}$ Cumulative survival of patients divided by presence and absence of muscle depletion. Patients without muscle depletion (MST 13.4 months) showed significantly longer overall survival than patients with muscle depletion (MST 10.4 months, $p=0.015$ ). c Cumulative survival of patients divided by visceral fat area. The patients with H-VFA (MST 14.2 months) showed significantly longer survival than those with L-VFA (MST 10.2 months, $p=$ 0.015). H-VFA, high visceral fat area; L-VFA, low visceral fat area; MST, median survival time.

\begin{tabular}{l|l}
\hline Liver Cancer 2018;7:359-371 \\
\hline DOI: 10.1159/000487858 & $\begin{array}{l}\text { @ 2018 S. Karger AG, Basel } \\
\text { www.karger.com/lic }\end{array}$ \\
\hline
\end{tabular}

Saeki et al.: Body Composition as a Sorafenib Biomarker
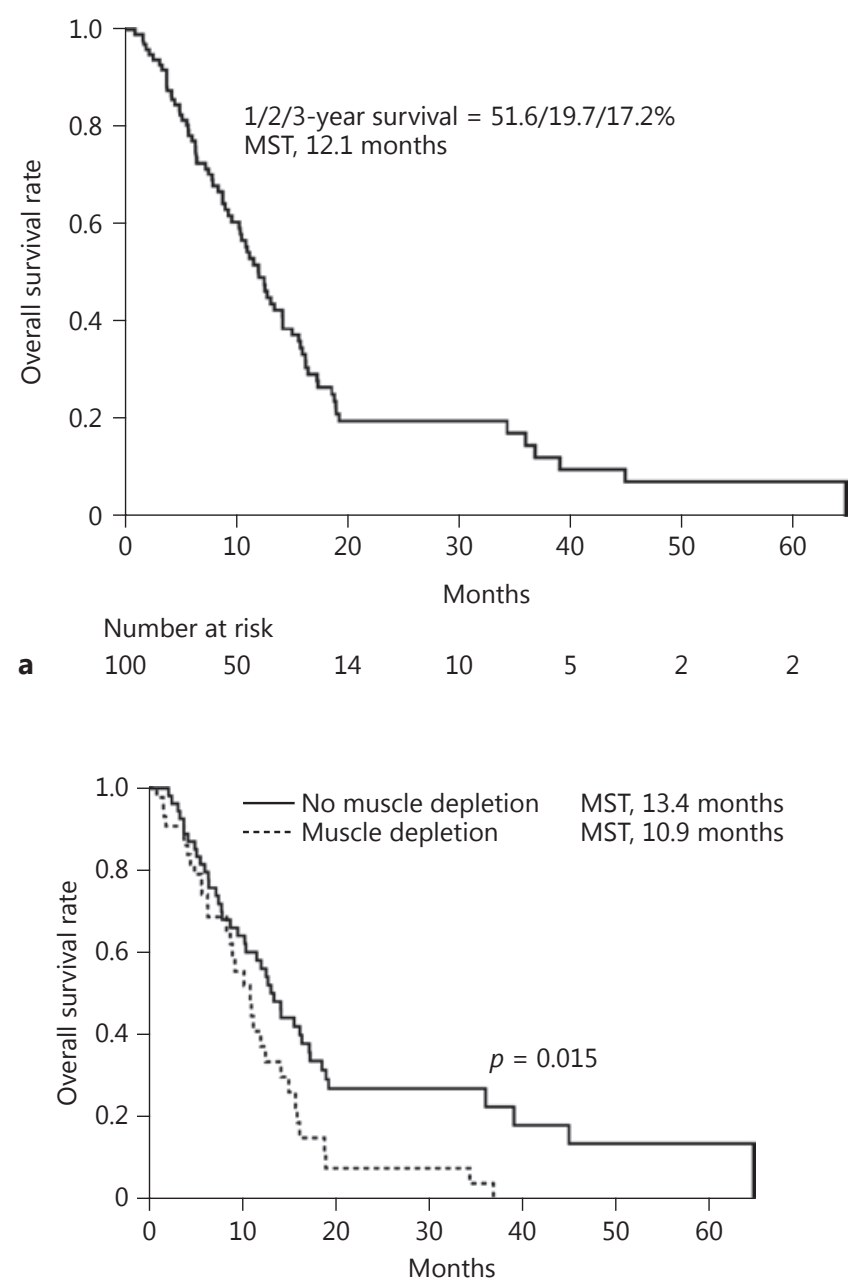

Number at risk

\begin{tabular}{|c|c|c|c|c|c|}
\hline-54 & 34 & 12 & 8 & 5 & 2 \\
\hline 46 & 17 & 3 & 3 & 0 & 0 \\
\hline
\end{tabular}

b

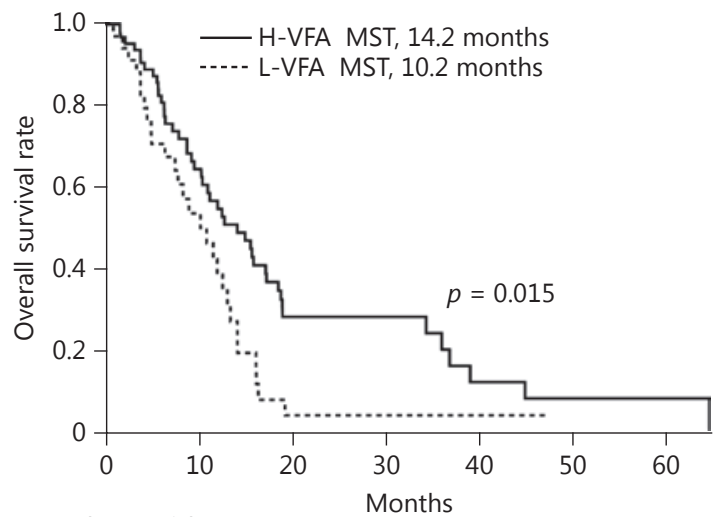

Number at risk

\begin{tabular}{|c|c|c|c|c|}
\hline-65 & 35 & 13 & & \\
\hline
\end{tabular}

c 


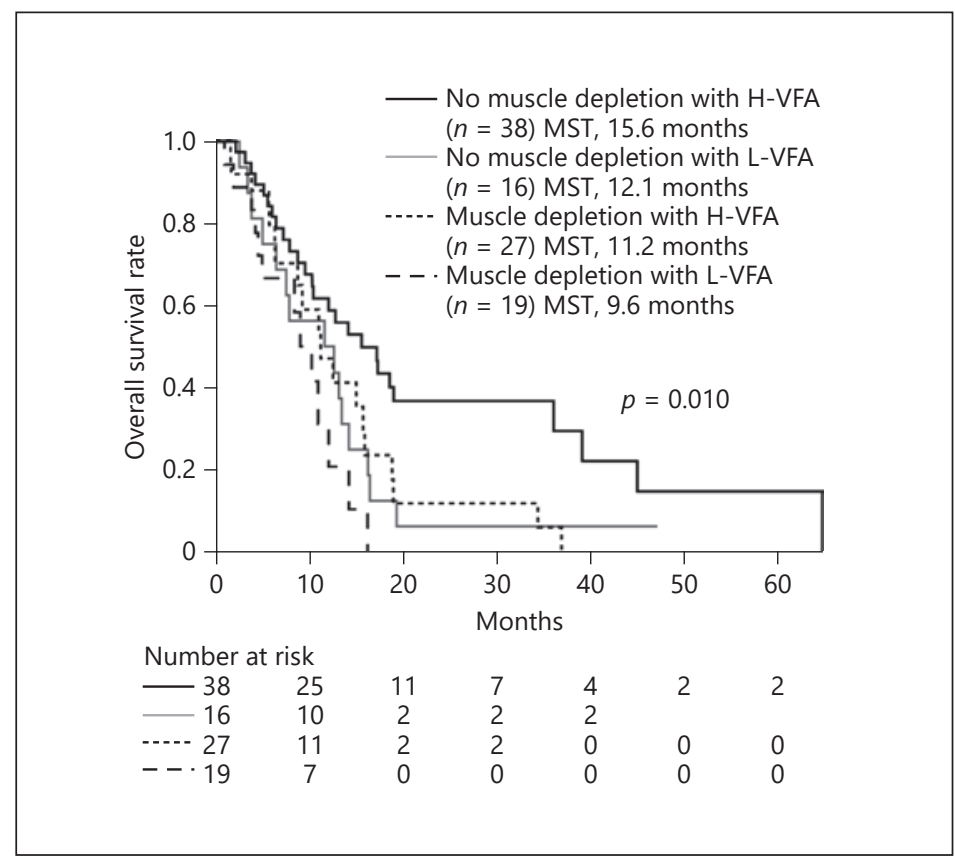

Fig. 2. Cumulative survival of patients classified into four groups: the no muscle depletion with H-VFA group ( $n=38)$, the no muscle depletion with L-VFA group $(n=16)$, the muscle depletion with H-VFA group $(n=27)$, and the muscle depletion with L-VFA group $(n=19)$. Patient survival was significantly stratified by body composition ( $p=0.010$ ). The no muscle depletion with H-VFA group (MST 15.6 months) showed the longest survival in the four groups, the no muscle depletion with L-VFA group 12.1 months, the muscle depletion with H-VFA group 11.2 months, and the muscle depletion with L-VFA group 9.6 months. In the no muscle depletion group, the H-VFA group showed significantly longer survival than the L-VFA group (15.6 vs. 12.1 months, $p=0.049$ ). Survival among the three groups other than no muscle depletion with H-VFA (no muscle depletion with L-VFA, muscle depletion with H-VFA, and muscle depletion with L-VFA) did not show any statistical differences ( $p=0.658)$. H-VFA, high visceral fat area; L-VFA, low visceral fat area; MST, median survival time.

Table 2. Uni- and multivariate analyses of prognostic factors in advanced HCC patients treated with sorafenib

\begin{tabular}{|c|c|c|c|c|c|c|}
\hline \multirow[t]{2}{*}{ Factors } & \multicolumn{3}{|c|}{ Univariate analysis } & \multicolumn{3}{|c|}{ Multivariate analysis } \\
\hline & HR & $95 \%$ CI & $p$ value & HR & $95 \% \mathrm{CI}$ & $p$ value \\
\hline Age $(<70 / \geq 70$ years $)$ & 0.771 & $0.470-1.235$ & 0.282 & & & \\
\hline $\operatorname{Sex}(M / F)$ & 0.764 & $0.465-1.300$ & 0.311 & & & \\
\hline Child-Pugh class (A/B) & 0.516 & $0.301-0.936$ & 0.031 & 0.537 & $0.297-1.020$ & 0.057 \\
\hline Tumor number $(<7 / \geq 7)$ & 0.444 & $0.274-0.712$ & $<0.001$ & 0.409 & $0.247-0.666$ & $<0.001$ \\
\hline Tumor size $(<40 / \geq 40 \mathrm{~mm})$ & 0.709 & $0.443-1.130$ & 0.148 & & & \\
\hline $\operatorname{MVI}(-/+)$ & 0.802 & $0.483-1.376$ & 0.413 & & & \\
\hline $\operatorname{EHS}(-/+)$ & 0.641 & $0.401-1.028$ & 0.065 & 0.562 & $0.344-0.921$ & 0.022 \\
\hline Muscle depletion $(-/+)^{\mathrm{a}}$ & 0.554 & $0.342-0.901$ & 0.018 & 0.498 & $0.304-0.818$ & 0.006 \\
\hline VFA (high/low) ${ }^{\mathrm{b}}$ & 0.552 & $0.342-0.905$ & 0.019 & 0.556 & $0.331-0.945$ & 0.031 \\
\hline
\end{tabular}

CI, confidence interval; EHS, extrahepatic spread; HCC, hepatocellular carcinoma; HR, hazard ratio; MVI,

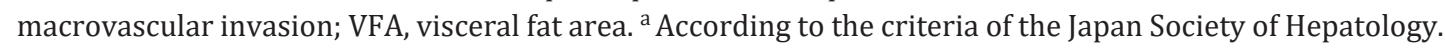
b According to the criteria for "obesity disease" as established by the Japan Society for the Study of Obesity. 


\section{Liver Cancer}

Fig. 3. Cumulative survival of patients classified into two groups according to body composition, i.e., no muscle depletion with H-VFA and others. These two groups showed significantly different prognoses (no muscle depletion with H-VFA vs. others: MST 15.6 vs. 11.0 months, $p=$ 0.003). H-VFA, high visceral fat area; MST, median survival time.

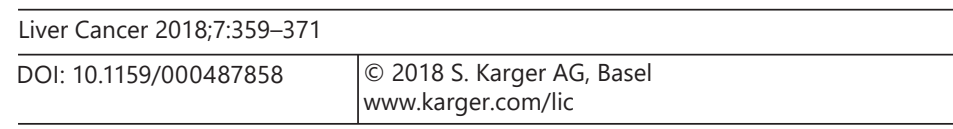

Saeki et al.: Body Composition as a Sorafenib Biomarker

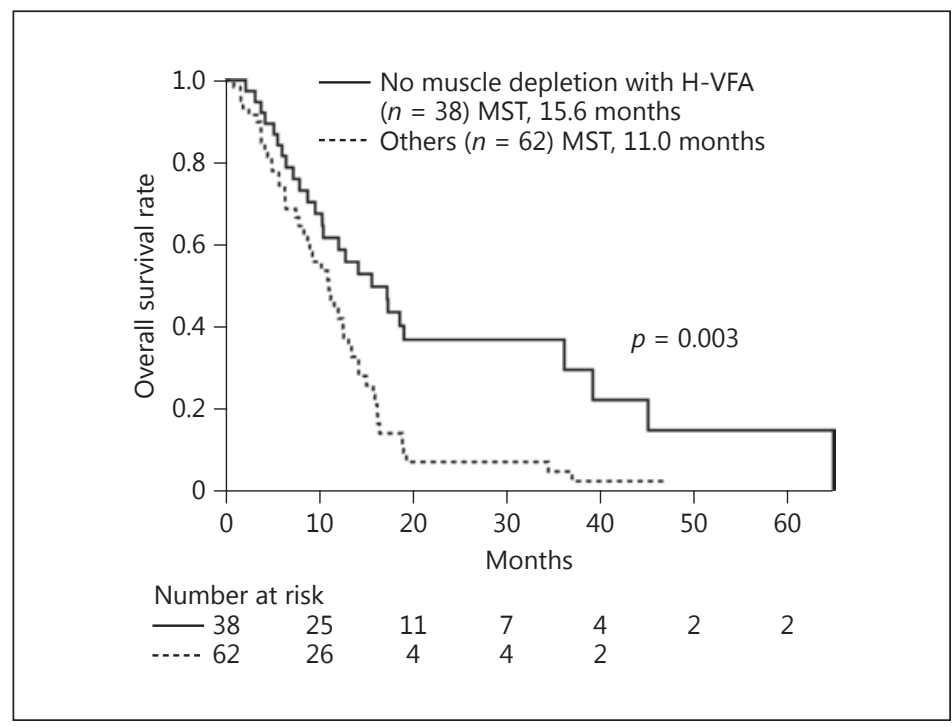

the no muscle depletion with L-VFA group, the muscle depletion with H-VFA group, and the muscle depletion with L-VFA group (MST 12.1 vs. 11.2 vs. 9.6 months, $p=0.658$ ). Therefore, we established no muscle depletion with H-VFA $(n=38)$ or others $(n=62)$ (no muscle depletion with L-VFA, muscle depletion with H-VFA, or muscle depletion with L-VFA), in relation to body composition, as a prognostic factor. These two groups showed significantly different prognoses (no muscle depletion with H-VFA vs. others: MST 15.6 vs. 11.0 months, $p=0.003$ ) (Fig. 3). We found that having a tumor number $<7$ (HR $=0.454,95 \%$ CI $0.278-$ $0.733, p=0.001$ ), absence of EHS (HR $=0.511,95 \%$ CI $0.311-0.839, p=0.008$ ), and no muscle depletion with H-VFA (HR $=0.454,95 \%$ CI $0.266-0.756, p=0.002)$ were favorable prognostic factors in multivariate analysis (Table 3). Therefore, we identified no muscle depletion with H-VFA as a beneficial biomarker in advanced HCC patients treated with sorafenib.

\section{Discussion}

We demonstrated that no muscle depletion with H-VFA is a favorable predictor of survival in advanced HCC patients treated with sorafenib. Although sarcopenia has been reported to be an independent predictor of survival in patients with various cancers including HCC [1115], there have been only three studies on HCC patients treated with sorafenib [16-18]. However, there have been no studies focusing on both skeletal muscle and visceral fat in HCC patients treated with sorafenib. This is the first study to identify no muscle depletion with H-VFA as a positive predictive marker for HCC patients treated with sorafenib.

Diagnostic criteria for sarcopenia or obesity differ among counties; there has been no international agreement on diagnostic criteria for sarcopenia or obesity based on CT imaging $[25,28,29]$. In 2016, the Japan Society of Hepatology published the assessment criteria for sarcopenia in liver disease based on data from Japanese people [25]; we used the CT assessment of these criteria for determining muscle depletion in this study. Regarding VFA using CT assessment, the criteria for "obesity disease" by the Japan Society for the Study of Obesity [28], which have been used commonly [24], were adopted in this study.

Sarcopenia was defined as an age-related skeletal muscle depletion by Rosenberg in 1989 [30,31]. Recently, sarcopenia was shown to be caused by some factors other than aging 
Table 3. Multivariate analysis of prognostic factors in advanced HCC patients treated with sorafenib

\begin{tabular}{|c|c|c|c|c|c|c|}
\hline \multirow[t]{2}{*}{ Factors } & \multicolumn{3}{|c|}{ Univariate analysis } & \multicolumn{3}{|c|}{ Multivariate analysis } \\
\hline & HR & $95 \% \mathrm{CI}$ & $p$ value & HR & $95 \%$ CI & $p$ value \\
\hline Age $(<70 / \geq 70$ years $)$ & 0.771 & $0.473-1.235$ & 0.282 & & & \\
\hline $\operatorname{Sex}(M / F)$ & 0.764 & $0.465-1.300$ & 0.311 & & & \\
\hline Child-Pugh class (A/B) & 0.516 & $0.301-0.936$ & 0.031 & 0.584 & $0.330-1.086$ & 0.087 \\
\hline Tumor number $(<7 / \geq 7)$ & 0.444 & $0.274-0.712$ & $<0.001$ & 0.454 & $0.278-0.733$ & 0.001 \\
\hline Tumor size $(<40 / \geq 40 \mathrm{~mm})$ & 0.709 & $0.443-1.130$ & 0.148 & & & \\
\hline $\operatorname{MVI}(-/+)$ & 0.802 & $0.483-1.376$ & 0.413 & & & \\
\hline EHS $(-/+)$ & 0.641 & $0.401-1.028$ & 0.065 & 0.511 & $0.311-0.839$ & 0.008 \\
\hline \multicolumn{7}{|l|}{ Body composition factor (no muscle } \\
\hline depletion with H-VFA/others) & 0.473 & $0.284-0.772$ & 0.003 & 0.454 & $0.266-0.756$ & 0.002 \\
\hline
\end{tabular}

CI, confidence interval; EHS, extrahepatic spread; HCC, hepatocellular carcinoma; HR, hazard ratio; H-VFA, high visceral fat area; MVI, macrovascular invasion.

(so-called secondary sarcopenia), due to various inflammatory diseases including liver cirrhosis (LC) [32]. Reduced glycogen storage in the liver can promote the degradation of skeletal muscle by requiring skeletal muscle to supply glucose and amino acids. Energy metabolism can be analyzed by indirect calorimetry; the non-protein respiratory quotient and oxidation volumes of carbohydrate, fat, and protein are calculated. It has been reported that the non-protein respiratory quotient significantly decreases with the progression of disease severity of LC [33] or with progression of HCC [34]; as a result, the oxidation rate of carbohydrates decreases and that of fat significantly increases. Therefore, advanced HCC patients may require a certain amount of not only skeletal muscle, but also visceral fat, as an energy substrate.

In our study, we analyzed the ability of body composition, in relation to both skeletal muscle and visceral fat, to predict survival of advanced HCC patients treated with sorafenib. Furthermore, the SMI was not significantly correlated with VFA (men: $r=0.122, p=0.305$; women: $r=0.357, p=0.062$ ). The individual body composition was categorized into four types: no muscle depletion with H-VFA, no muscle depletion with L-VFA, muscle depletion with H-VFA, and muscle depletion with L-VFA. When analyzing OS by these four types, the no muscle depletion with H-VFA group showed the best prognosis, and the other groups showed almost similar prognoses ( $p=0.658$ ) (Fig. 2). Therefore, we established no muscle depletion with H-VFA, in relation to body composition, as a prognostic factor. Although the impact of H-VFA was lower than that of no muscle depletion (HR = 0.556 vs. 0.498 ; Table 2 ), survival was significantly better in the no muscle depletion with H-VFA group than in the no muscle depletion with L-VFA group (15.6 vs. 12.1 months, $p=0.049$; Fig. 2). We considered that measuring VFA helps select patients with a favorable prognosis from those with no muscle depletion. This body composition was an independent predictor of survival (Table 3); the patients without muscle depletion who had H-VFA showed significantly longer survival than those with other body compositions (Fig. 3). Although patients in the no muscle depletion with H-VFA group were younger than patients in the other groups $(p=0.045)$, both types had comparable tumor factors and Child-Pugh classifications (Table 4).

Furthermore, the disease control rate for the no muscle depletion with H-VFA group was significantly higher than that for the other groups (76.3 vs. $50.0 \%, p=0.012$ ). This may be associated with the fact that the duration of treatment with sorafenib (time to treatment failure) and the total amount of administered sorafenib in the no muscle depletion with 
Saeki et al.: Body Composition as a Sorafenib Biomarker

Table 4. Patient characteristics between the no muscle depletion with H-VFA group and the other groups

\begin{tabular}{lccc}
\hline Factors & $\begin{array}{c}\text { No muscle depletion } \\
\text { with H-VFA }\end{array}$ & Others & $p$ value \\
& 38 & 62 & \\
\hline Number & $68.1 \pm 9.6$ & $72.1 \pm 9.7$ & 0.045 \\
Age, years & $28 / 10$ & $44 / 18$ & 0.822 \\
Sex (M/F) & & & \\
Etiology (HBV/HCV/alcohol/ & $11 / 15 / 7 / 5$ & $9 / 39 / 5 / 9$ & 0.072 \\
$\quad$ others) & $35 / 33$ & $47 / 15$ & 0.208 \\
Child-Pugh class (A/B) & $20 / 18$ & $29 / 33$ & 0.681 \\
Tumor number $(<7 / \geq 7)$ & $22 / 16$ & $25 / 37$ & 0.102 \\
Tumor size $(<40 / \geq 40$ mm) & $29 / 9$ & $42 / 20$ & 0.496 \\
MVI (-/+) & $19 / 19$ & $37 / 25$ & 0.408 \\
EHS (-/+) & $49.5 \pm 6.2 / 41.2 \pm 3.1$ & $40.7 \pm 5.7 / 35.4 \pm 4.7$ & $<0.001 / 0.002$ \\
L3 SMI (M/F), cm ${ }^{2} / \mathrm{m}^{2}$ & $152.9 \pm 47.2$ & $106.5 \pm 56.4$ & $<0.001$ \\
VFA, cm ${ }^{2}$ & $29 / 9$ & $31 / 31$ & 0.012 \\
Disease control $(+/-)$ & $(0 / 5 / 24 / 8 / 1)$ & $(0 / 2 / 29 / 19 / 12)$ & \\
$\quad(C R / P R / S D / P D / N E)^{a}$ & & & \\
\hline
\end{tabular}

Values are presented as numbers or mean \pm standard deviation. CR, complete response; EHS, extrahepatic spread; HBV, hepatitis B virus; HCV, hepatitis C virus; H-VFA, high visceral fat area; L3 SMI, third lumber vertebra skeletal muscle index; MVI, macrovascular invasion; NE, no evaluation; PD, progressive disease; PR, partial response; SD, stable disease; VFA, visceral fat area. ${ }^{a}$ Disease control evaluated by modified Response Evaluation Criteria in Solid Tumors (CR+PR+SD)/(CR+PR+SD+PD+NE).

H-VFA group were significantly greater than those in the other groups (median time to treatment failure 11.0 vs. 4.7 months, $p=0.003$, see online suppl. Fig. 1 ; for all online suppl. material, see www.karger.com/doi/10.1159/000487858; median total amount of administered sorafenib 115,003 vs. $52,124 \mathrm{mg}, p<0.001$ ). However, we found no significant differences regarding the reasons for sorafenib withdrawal such as adverse events, deterioration of liver function, and disease progression between the no muscle depletion with H-VFA group and the other groups (data not shown). Similar results have been found in other studies $[16,18]$.

Recently, the ALBI grade, a liver function assessment based on albumin and bilirubin, has been proposed in HCC patients [35]; a large multicenter study validated the prognostic value of the ALBI grade across all Barcelona Clinic Liver Cancer stages [36]. Regarding the ALBI grade, 63 of 80 patients with Child-Pugh A were classified as having ALBI grade 2 and 1 of 20 patients with Child-Pugh B as having ALBI grade 1. We adopted the ALBI grade as a substitute for Child-Pugh and then analyzed the data again. Univariate analysis confirmed the ALBI grade as a prognostic factor; however, multivariate analyses did not (see online suppl. Tables 1,2 ). We found almost the same results: tumor number $<7$ (HR $=0.451,95 \% \mathrm{CI} 0.276-0.726$, $p=0.001$ ), absence of EHS (HR $=0.564,95 \%$ CI $0.348-0.918, p=0.022$ ), and no muscle depletion with H-VFA (HR $=0.459,95 \%$ CI $0.259-0.787, p=0.004)$ were favorable prognostic factors in multivariate analysis (see online suppl. Table 2).

Next, we analyzed the changes in SMI and VFA 3 and 6 months after the induction of sorafenib. Skeletal muscle mass decreased by 5.8 and $5.6 \%$, respectively (see online suppl. Fig. 2a), while VFA did not show significant changes during sorafenib administration (see online suppl. Fig. 2b). Additionally, progression of muscle loss was observed in both muscle depletion and no muscle depletion groups (data not shown). These results are in accordance with a previous report [16]. The annual rates of skeletal muscle mass decline were reported to be $1.3 \%$ for Child-Pugh A, 3.5\% for Child-Pugh B, and 6.1\% for Child-Pugh C in LC patients 


\section{Liver Cancer}

Saeki et al.: Body Composition as a Sorafenib Biomarker

without HCC [37]. Although obvious differences are seen with regards to backgrounds (LC without HCC vs. LC with advanced HCC), sorafenib treatment may markedly reduce skeletal muscle mass compared with LC patients. Therefore, it is suggested that advanced HCC patients treated with sorafenib require enough skeletal muscle mass for treatment.

In general, obesity is associated with tumor progression and poor prognosis in various cancers [38]. Fujiwara et al. [15] reported that high visceral adiposity was independently associated with poor prognosis, but the incidence of advanced HCC was too small ( 61 of 1,257 patients, $4.8 \%$ ), with various treatments being performed in their study. However, H-VFA, which was defined as a value of $\geq 103 \mathrm{~cm}^{2}$ for men and $\geq 69 \mathrm{~cm}^{2}$ for women, was independently associated with a longer survival in HCC patients who underwent hepatic resection [20]. In addition, it has also been reported that H-VFA, which was defined as a value of $\geq 14,138 \mathrm{~mm}^{2}$, was an independent favorable prognostic factor in patients with metastatic renal cell carcinoma who were treated with vascular endothelial growth factor-targeted therapy [39]. Although these types of cancer differ, the patient characteristics were similar to the characteristics of patients with advanced stages of both renal cell carcinoma and HCC in our study. We considered that VFA may affect prognosis by the difference in tumor stage, treatment, and type of cancer. However, its mechanisms remain unclear, and there is still more room for further research in the field of adipokines and how they affect HCC [40] and nutrition. Nutritional therapies [41] or exercise [42] may be useful as an adjunctive therapy for sarcopenia. However, there are a few reports on the efficacy of branched-chain amino acid granules $[43,44]$ and no reports on the efficacy of exercise in HCC patients treated with sorafenib. As these latter reports are about cohort studies, a randomized control trial will be needed.We have reported that a late evening snack using branched-chain amino acid nutrients improved the energy metabolism in advanced HCC patients undergoing hepatic arterial infusion chemotherapy compared with ordinary food [34]. As there are no studies about late evening snacks using branched-chain amino acid nutrients in sorafenib-treated patients with advanced HCC, further investigations are necessary.

There are limitations to this study. This was a retrospective, single-center study with a small population. Therefore, further investigations with a large sample size are necessary. As CT is an essential imaging procedure for patients with HCC, evaluation of SMI and VFA is a simple method to conduct. Although a validation study with a large sample size in multiple centers is required, it is possible to validate our findings without additional radiation exposure.

In conclusion, we identified no muscle depletion with H-VFA as a novel biomarker for advanced HCC patients treated with sorafenib. Although the tumor characteristics are immutable, it is possible to introduce a treatment intervention, such as nutritional therapy and/or exercise, to help improve factors related to body composition before or during sorafenib treatment. For advanced HCC patients, except for those with no muscle depletion with H-VFA, such appropriate interventions may improve the clinical outcomes.

\section{Statement of Ethics}

This study was conducted in compliance with the ethical principles of the Declaration of Helsinki. The protocol (H28-026) was approved by the Institutional Review Board of Yamaguchi University Hospital.

\section{Disclosure Statement}

The authors do not have any disclosures to report. This study did not receive any grant support or assistance. 
Saeki et al.: Body Composition as a Sorafenib Biomarker

\section{Author Contributions}

I. Saeki and T. Yamasaki designed the study, analyzed the data, and wrote the paper; I. Saeki, M. Maeda, T. Iwamoto, I. Hidaka, and T. Ishikawa acquired the data; I. Saeki and R. Kawano performed the statistical analysis; T. Hisanaga, T. Matsumoto, and T. Takami reviewed the results; I. Sakaida revised the manuscript for important intellectual content.

\section{References}

1 Llovet J, Ricci S, Mazzaferro V, Hilgard P, Gane E, Blanc J, de Oliveira A, Santoro A, Raoul J, Forner A, Schwartz M, Porta C, Zeuzem S, Bolondi L, Greten T, Galle P, Seitz J, Borbath I, Häussinger D, Giannaris T, Shan M, Moscovici M, Voliotis D, Bruix J: Sorafenib in advanced hepatocellular carcinoma. N Engl J Med 2008;359: 378-390.

-2 Cheng AL, Kang YK, Chen Z, Tsao CJ, Qin S, Kim JS, Luo R, Feng J, Ye S, Yang TS, Xu J, Sun Y, Liang H, Liu J, Wang J, Tak WY, Pan H, Burock K, Zou J, Voliotis D, Guan Z: Efficacy and safety of sorafenib in patients in the AsiaPacific region with advanced hepatocellular carcinoma: a phase III randomised, double-blind, placebocontrolled trial. Lancet Oncol 2009;10:25-34.

-3 Bruix J, Sherman M; American Association for the Study of Liver Diseases: Management of hepatocellular carcinoma: an update. Hepatology 2011;53:1020-1022.

-4 Kudo M, Ikeda M, Takayama T, Numata K, Izumi N, Furuse J, Okusaka T, Kadoya M, Yamashita S, Ito Y, Kokudo $\mathrm{N}$ : Safety and efficacy of sorafenib in Japanese patients with hepatocellular carcinoma in clinical practice: a subgroup analysis of GIDEON. J Gastroenterol 2016;51:1150-1160.

5 Parikh ND, Marshall VD, Singal AG, Nathan H, Lok AS, Balkrishnan R, Shahinian V: Survival and cost-effectiveness of sorafenib therapy in advanced hepatocellular carcinoma: an analysis of the SEER-Medicare database. Hepatology 2017;65:122-133.

6 Llovet JM, Peña CE, Lathia CD, Shan M, Meinhardt G, Bruix J; SHARP Investigators Study Group: Plasma biomarkers as predictors of outcome in patients with advanced hepatocellular carcinoma. Clin Cancer Res 2012;18:2290-2300.

7 Shao YY, Hsu CH, Cheng AL: Predictive biomarkers of sorafenib efficacy in advanced hepatocellular carcinoma: are we getting there? World J Gastroenterol 2015;21:10336-10347.

-8 Kuzuya T, Ishigami M, Ishizu Y, Honda T, Hayashi K, Katano Y, Hirooka Y, Ishikawa T, Nakano I, Goto H: Early clinical response after 2 weeks of sorafenib therapy predicts outcomes and anti-tumor response in patients with advanced hepatocellular carcinoma. PLoS One 2015;10:e0138776.

-9 Bruix J, Cheng AL, Meinhardt G, Nakajima K, De Sanctis Y, Llovet J: Prognostic factors and predictors of sorafenib benefit in patients with hepatocellular carcinoma: analysis of two phase III studies. J Hepatol 2017; 67:999-1008.

10 Prado CM, Cushen SJ, Orsso CE, Ryan AM: Sarcopenia and cachexia in the era of obesity: clinical and nutritional impact. Proc Nutr Soc 2016;75:188-198.

11 Prado CM, Lieffers JR, McCargar LJ, Reiman T, Sawyer MB, Martin L, Baracos VE: Prevalence and clinical implications of sarcopenic obesity in patients with solid tumours of the respiratory and gastrointestinal tracts: a population-based study. Lancet Oncol 2008;9:629-635.

12 Choi Y, Oh DY, Kim TY, Lee KH, Han SW, Im SA, Bang YJ: Skeletal muscle depletion predicts the prognosis of patients with advanced pancreatic cancer undergoing palliative chemotherapy, independent of body mass index. PLoS One 2015;10:e0139749.

13 Miyamoto Y, Baba Y, Sakamoto Y, Ohuchi M, Tokunaga R, Kurashige J, Hiyoshi Y, Iwagami S, Yoshida N, Yoshida M, Watanabe M, Baba H: Sarcopenia is a negative prognostic factor after curative resection of colorectal cancer. Ann Surg Oncol 2015;22:2663-2668.

14 Meza-Junco J, Montano-Loza AJ, Baracos VE, Prado CM, Bain VG, Beaumont C, Esfandiari N, Lieffers JR, Sawyer MB: Sarcopenia as a prognostic index of nutritional status in concurrent cirrhosis and hepatocellular carcinoma. J Clin Gastroenterol 2013;47:861-870.

15 Fujiwara N, Nakagawa H, Kudo Y, Tateishi R, Taguri M, Watadani T, Nakagomi R, Kondo M, Nakatsuka T, Minami T, Sato M, Uchino K, Enooku K, Kondo Y, Asaoka Y, Tanaka Y, Ohtomo K, Shiina S, Koike K: Sarcopenia, intramuscular fat deposition, and visceral adiposity independently predict the outcomes of hepatocellular carcinoma. J Hepatol 2015;63:131-140.

16 Hiraoka A, Hirooka M, Koizumi Y, Izumoto H, Ueki H, Kaneto M, Kitahata S, Aibiki T, Tomida H, Miyamoto Y, Yamago H, Suga Y, Iwasaki R, Mori K, Miyata H, Tsubouchi E, Kishida M, Ninomiya T, Abe M, Matsuura B, Kawasaki H, Hiasa Y, Michitaka K: Muscle volume loss as a prognostic marker in hepatocellular carcinoma patients treated with sorafenib. Hepatol Res 2017;47:558-565.

17 Imai K, Takai K, Hanai T, Ideta T, Miyazaki T, Kochi T, Suetsugu A, Shiraki M, Shimizu M: Skeletal muscle depletion predicts the prognosis of patients with hepatocellular carcinoma treated with sorafenib. Int J Mol Sci 2015;16:9612-9624. 
18 Nishikawa H, Nishijima N, Enomoto H, Sakamoto A, Nasu A, Komekado H, Nishimura T, Kita R, Kimura T, Iijima H, Nishiguchi S, Osaki Y: Prognostic significance of sarcopenia in patients with hepatocellular carcinoma undergoing sorafenib therapy. Oncol Lett 2017;14:1637-1647.

19 Itoh S, Shirabe K, Matsumoto Y, Yoshiya S, Muto J, Harimoto N, Yamashita Y, Ikegami T, Yoshizumi T, Nishie A, Maehara Y: Effect of body composition on outcomes after hepatic resection for hepatocellular carcinoma. Ann Surg Oncol 2014;21:3063-3068.

-20 Higashi T, Hayashi H, Kaida T, Arima K, Takeyama H, Taki K, Izumi D, Tokunaga R, Kosumi K, Nakagawa S, Okabe H, Imai K, Nitta H, Hashimoto D, Chikamoto A, Beppu T, Baba H: Prognostic impact of visceral fat amount and branched-chain amino acids (BCAA) in hepatocellular carcinoma. Ann Surg Oncol 2015;22(suppl 3): S1041-S1047.

21 Nault JC, Pigneur F, Nelson AC, Costentin C, Tselikas L, Katsahian S, Diao G, Laurent A, Mallat A, Duvoux C, Luciani A, Decaens T: Visceral fat area predicts survival in patients with advanced hepatocellular carcinoma treated with tyrosine kinase inhibitors. Dig Liver Dis 2015;47:869-876.

-22 Kudo M, Kitano M, Sakurai T, Nishida N: General rules for the clinical and pathological study of primary liver cancer, nationwide follow-up survey and clinical practice guidelines: the outstanding achievements of the Liver Cancer Study Group of Japan. Dig Dis 2015;33:765-770.

-23 Mitsiopoulos N, Baumgartner RN, Heymsfield SB, Lyons W, Gallagher D, Ross R: Cadaver validation of skeletal muscle measurement by magnetic resonance imaging and computerized tomography. J Appl Physiol (1985) 1998;85:115-122.

24 Yoshizumi T, Nakamura T, Yamane M, Islam AH, Menju M, Yamasaki K, Arai T, Kotani K, Funahashi T, Yamashita S, Matsuzawa Y: Abdominal fat: standardized technique for measurement at CT. Radiology 1999;211:283286.

25 Nishikawa H, Shiraki M, Hiramatsu A, Moriya K, Hino K, Nishiguchi S: Japan Society of Hepatology guidelines for sarcopenia in liver disease (1st edition): recommendation from the working group for creation of sarcopenia assessment criteria. Hepatol Res 2016;46:951-963.

-26 Hiuge-Shimizu A, Kishida K, Funahashi T, Ishizaka Y, Oka R, Okada M, Suzuki S, Takaya N, Nakagawa T, Fukui T, Fukuda H, Watanabe N, Yoshizumi T, Nakamura T, Matsuzawa Y, Yamakado M, Shimomura I: Absolute value of visceral fat area measured on computed tomography scans and obesity-related cardiovascular risk factors in large-scale Japanese general population (the VACATION-J study). Ann Med 2012;44:82-92.

-27 Edeline J, Boucher E, Rolland Y, Vauléon E, Pracht M, Perrin C, Le Roux C, Raoul JL: Comparison of tumor response by Response Evaluation Criteria in Solid Tumors (RECIST) and modified RECIST in patients treated with sorafenib for hepatocellular carcinoma. Cancer 2012;118:147-156.

28 Examination Committee of Criteria for "Obesity Disease" in Japan; Japan Society for the Study of Obesity: New criteria for "obesity disease" in Japan. Circ J 2002;66:987-992.

29 Murray T, Williams D, Lee MJ: Osteoporosis, obesity, and sarcopenia on abdominal CT: a review of epidemiology, diagnostic criteria, and management strategies for the reporting radiologist. Abdom Radiol (NY) 2017; 42:2376-2386.

30 Rosenberg IH: Summary comments: epidemiological and methodological problems in determining nutritional status of older persons. Am J Clin Nutr 1989;50:1231-1233.

-31 Rosenberg IH: Sarcopenia: origins and clinical relevance. J Nutr 1997;127(5 suppl):990S-991S.

32 Cruz-Jentoft AJ, Baeyens JP, Bauer JM, Boirie Y, Cederholm T, Landi F, Martin FC, Michel JP, Rolland Y, Schneider SM, Topinková E, Vandewoude M, Zamboni M; European Working Group on Sarcopenia in Older People: Sarcopenia: European consensus on definition and diagnosis: report of the European Working Group on Sarcopenia in Older People. Age Ageing 2010;39:412-423.

-33 Tajika M, Kato M, Mohri H, Miwa Y, Kato T, Ohnishi H, Moriwaki H: Prognostic value of energy metabolism in patients with viral liver cirrhosis. Nutrition 2002;18:229-234.

34 Harima Y, Yamasaki T, Hamabe S, Saeki I, Okita K, Terai S, Sakaida I: Effect of a late evening snack using branched-chain amino acid-enriched nutrients in patients undergoing hepatic arterial infusion chemotherapy for advanced hepatocellular carcinoma. Hepatol Res 2010;40:574-584.

-35 Johnson PJ, Berhane S, Kagebayashi C, Satomura S, Teng M, Reeves HL, O’Beirne J, Fox R, Skowronska A, Palmer D, Yeo W, Mo F, Lai P, Iñarrairaegui M, Chan SL, Sangro B, Miksad R, Tada T, Kumada T, Toyoda H: Assessment of liver function in patients with hepatocellular carcinoma: a new evidence-based approach - the ALBI grade. J Clin Oncol 2015;33:550-558.

-36 Pinato DJ, Sharma R, Allara E, Yen C, Arizumi T, Kubota K, Bettinger D, Jang JW, Smirne C, Kim YW, Kudo M, Howell J, Ramaswami R, Burlone ME, Guerra V, Thimme R, Ishizuka M, Stebbing J, Pirisi M, Carr BI: The ALBI grade provides objective hepatic reserve estimation across each BCLC stage of hepatocellular carcinoma. J Hepatol 2017;66:338-346.

-37 Hanai T, Shiraki M, Ohnishi S, Miyazaki T, Ideta T, Kochi T, Imai K, Suetsugu A, Takai K, Moriwaki H, Shimizu M: Rapid skeletal muscle wasting predicts worse survival in patients with liver cirrhosis. Hepatol Res 2016; 46:743-751.

-38 Fukumura D, Incio J, Shankaraiah RC, Jain RK: Obesity and cancer: an angiogenic and inflammatory link. Microcirculation 2016;23:191-206.

-39 Steffens S, Grünwald V, Ringe KI, Seidel C, Eggers H, Schrader M, Wacker F, Kuczyk MA, Schrader AJ: Does obesity influence the prognosis of metastatic renal cell carcinoma in patients treated with vascular endothelial growth factor-targeted therapy? Oncologist 2011;16:1565-1571. 
40 Duan XF, Tang P, Li Q, Yu ZT: Obesity, adipokines and hepatocellular carcinoma. Int J Cancer 2013;133:17761783.

41 Takami T, Yamasaki T, Saeki I, Matsumoto T, Suehiro Y, Sakaida I: Supportive therapies for prevention of hepatocellular carcinoma recurrence and preservation of liver function. World J Gastroenterol 2016;22:72527263.

-42 Koya S, Kawaguchi T, Hashida R, Goto E, Matsuse H, Saito H, Hirota K, Taira R, Matsushita Y, Imanaga M, Nagamatsu A, Shirono T, Shimose S, Iwamoto H, Niizeki T, Kuromatsu R, Miura H, Shiba N, Torimura T: Effects of in-hospital exercise on liver function, physical ability, and muscle mass during treatment of hepatoma in patients with chronic liver disease. Hepatol Res 2017;47:E22-E34.

-43 Takeda H, Nishikawa H, Iguchi E, Ohara Y, Sakamoto A, Saito S, Nishijima N, Nasu A, Komekado H, Kita R, Kimura T, Osaki Y: Effect of treatment with branched-chain amino acids during sorafenib therapy for unresectable hepatocellular carcinoma. Hepatol Res 2014;44:302-312.

44 Imanaka K, Ohkawa K, Tatsumi T, Katayama K, Inoue A, Imai Y, Oshita M, Iio S, Mita E, Fukui H, Yamada A, Nakanishi F, Inada M, Doi Y, Suzuki K, Kaneko A, Marubashi S, Ito Y, Fukui K, Sakamori R, Yakushijin T, Hiramatsu N, Hayashi N, Takehara T, Forum OL: Impact of branched-chain amino acid supplementation on survival in patients with advanced hepatocellular carcinoma treated with sorafenib: a multicenter retrospective cohort study. Hepatol Res 2016;46:1002-1010. 